\title{
Penggunaan STEM (Science, Technology, Engineering, and Mathematics) Terintegrasi Pembelajaran berbasis Proyek untuk Mahasiswa
}

\author{
Anggi Tias Pratama ${ }^{1 *}$, Kintan Limiansi ${ }^{1}$, Rizqa Devi Anazifa ${ }^{1}$ \\ ${ }^{1}$ Program Studi Pendidikan Biologi, Universitas Negeri Yogyakarta \\ "Emai: anggitias@uny.ac.id
}

\begin{abstract}
Abstrak: Penelitian ini menyajikan tentang wawasan praktik STEM yang terintegrasi dengan pembelajaran berbasis proyek. Kami menunjukkan bahwa ketika penyelidikan memicu minat mahasiswa dan membutuhkan partisipasi aktif, ada peluang untuk mengalami pembelajaran berbasis proyek. Sampel pada penelitian adalah mahasiswa pendidikan biologi yang mengikuti perkuliahan ilmu lingkungan berjumlah 30 orang. Analisis data dilakukan secara kualitatif dengan analisis deskriptif untuk melihat dominansi setting pembelajaran, aktifitas pembelajaran, dan produk dari setiap seting pembelajaran tersebut. Mahasiswa mengerjakan proyek dengan langkah-langkah pembelajaran yang ada pada STEM. Hasil menunjukkan bahwa mahasiswa dapat mengerjakan proyek dengan baik, dan mampu mempublikasikan hasil karya mereka di youtube.
\end{abstract}

\section{Kata Kunci: STEM, Pembelajaran Berbasis Proyek, Ilmu Lingkungan}

Abstract: This study provides insights into STEM practices that are integrated with project-based learning. We show that when investigations into student interest and active participation, there are opportunities to experience project-based learning. The sample in the study was 30 students of biology education who attended environmental science lectures. The data analysis was carried out qualitatively with descriptive analysis to see the dominance of learning arrangements, learning activities, and the products of each of these learning settings. Students work on projects using the STEM learning steps. The results show that students can work on projects well, and are able to publish their work on YouTube.

\section{Keywords: STEM, Project-Based Learning, Environmental Science}

Memasuki dasa warsa ketiga, abad 21 diwarnai dengan beberapa capaian manusia yang sangat fenomenal dan momental. Capaian kemajuan di bidang IPTEK khususnya rekayasa dan ICT, telah membawa manusia memasuki era revolusi industri baru, yang dikenal dengan Era Revolusi Industri 4.0, di mana ICT dan kecerdasan artifisial telah mampu mempengaruhi dan mendominasi pada hampir seluruh aspek kehidupan manusia. 
Kemajuan di bidang rekayasa dan ICT ini juga terus melahirkan lonjakan-lonjakan kebutuhan dan pemikiran yang berujung pada era yang penuh ketidakpastian (era disrupsi). Dalam era ketidakpastian ini, terjadi perubahan-perubahan yang sangat cepat dan sering tidak terprediksi mengenai pemikiran dan kebutuhan manusia ini. Hal-hal yang dianggap penting akan cepat berubah menjadi tidak berguna, hanya dalam hitungan tahun bahkan bulan. Hal-hal selama bertahun-tahun dipandang sebagai suatu hal yang terpola dan berkelanjutan, menjadi terkoreksi dalam satu atau dua tahun (Gardiner et al, 2017; Murugesh, 2018).

Perubahan cepat dan ketidakpastian yang mewarnai era awal abad 21 ini juga menyangkut pada bidang usaha dan karir. Pada era ini bermunculan bidang kerja dan karir baru yang sama sekali tidak terpikirkan pada beberapa tahun yang lalu. Dengan kata lain, bidang kerja dan karir yang ada dan dipandang sistematis saat ini, bisa jadi akan berubah bahkan hilang dalam beberapa tahun ke depan. Era Revolusi Industri 4.0 dan pendidikan abad 21 di mana ICT dan kecerdasan artifisial telah mampu mempengaruhi dan mendominasi pada hampir seluruh aspek kehidupan manusia. Hal ini juga berdampak pada perubahan khususnya di bidang pendidikan. Pendidikan perlu menyediakan fasilitas terbaik agar proses pembelajaran sesuai dengan yang diinginkan standar proses guru. Penerapan kurikulum kampus merdeka merupakan upaya pemerintah untuk mengembangkan pendidikan di Indonesia, mengingat persaingan di abad 21 ini menuntut sumber daya manusia yang kompetitif di bidang sains, teknologi, desain teknik, dan matematika (Widayanti et al., 2019). STEM terintegrasi adalah salah satu cara untuk membuat pembelajaran lebih terhubung dan relevan bagi siswa (Stohlmann et al., 2012).

Pembelajaran yang berbasis STEM akan mendukung tujuan Industri 4.0 dengan keterampilan abad 21 yang dibutuhkan. Keterampilan abad 21 penting dimiliki oleh generasi penerus bangsa agar dapat menghadapi revolusi industry 4.0. Keterampilan abad 21 tersebut antara lain adalah berpikir kritis, kreativitas, inovasi, kerjasama, pemecahan masalah, dan keterampilan komunikasi (Idin, 2011). STEM merupakan suatu pedagogi baru untuk menanggapi kebutuhan dan meningkatkan minat siswa dalam sains, teknologi dan matematika (Perignat \& Katz-Buonincontro, 2019). STEM mengarahkan pendidik untuk mengemas pembelajaran berbasis proyek dengan melibatkan lima bidang ilmu yaitu sains, teknologi, rekayasa, seni, dan matematika (Zubaidah, 2019). Pembelajaran berbasis proyek merupakan pendekatan pembelajaran yang dikendalikan oleh siswa melalui bantuan guru. Dalam hal ini, siswa memperoleh pemahamannya melalui pertanyaan-pertanyaan yang dapat menjawab rasa penasaran mereka (Fernandes et al., 2014).

Pembelajaran berbasis proyek dapat membantu mahasiswa dalam proses pengkonstruksian pengetahuan secara individu sesuai dengan kapasitas masing masing mahasiswa. Keahlihan dalam pengumpulan dan penggunaan data untuk memandu dan menginterogasi hasil penyelidikan sains dan teknik dalam kegiatan STEM dapat sekaligus 
digunakan untuk mengembangkan literasi sains siswa, khususnya praktik sains yaitu mengajukan pertanyaan, mengembangkan sebuah rencana dan pengumpulan data, mewakili, menganalisis dan menafsirkan data dan mencapai suatu kesimpulan (Hourigan \& Leavy, 2020).

\section{METODE PENELITIAN}

Penelitian ini menggunakan pendekatan kualiatif dengan teknik pengumpulan data dengan mengobservasi kegiatan pembelajaran. Sampel dari penelitian ini adalah seluruh mahasiswa pendidikan biologi yang menempu matakuliah ilmu lingkungan berjumlah 30 orang. Analisis data dilakukan secara kualitatif dengan analisis deskriptif untuk melihat dominansi setting pembelajaran, aktifitas pembelajaran, dan produk dari setiap seting pembelajaran tersebut. Tahapan pembelajaran STEM terintegrasi dengan pembelajaran berbasis proyek. Mahasiswa diberikan permasalahan dan membuat proyek. Masalah "Perubahan lingkungan dan pencemaran lingkungan yang disebabkan oleh aktivitas manusia. Pencemaran lingkungan dapat berupa hasil limbah buangan yang tidak terpakai, misalnya sampah, pencemaran air dari limbah mencuci pakaian dan peralatan makan, serta masih banyak lagi. Sebagai generasi muda yang kreatif dan inovatif, coba kalian buat desain atau miniartur pengelolahan limbah sederhana yang ramah lingkungan dengan menggunakan bahan-bahan bekas".

Sebelum membuat perencanaan, jangan lupa lakukan kajian literatur melalui buku atau internet. Dapatkan sumber berbentuk artikel dan video untuk mempermudah perencanaan yang kalian susun

1. Tuliskan solusi yang akan kalian kerjakan untuk mengatasi permasalahan tersebut

2. Buat desain pengelolaan limbah secara sederhana yang ramah lingkungan secara berkelompok

3. Tuliskan alat dan bahan yang kalian butuhkan

4. Tuliskan rencana pengerjaan kalian

5. Secara berkelompok mencari limbah pada yang ada disekitar tempat tinggal mahasiswa

6. Tuliskan konsep IPA yang terkait dengan desain kalian

7. Tuliskan konsep matematika yang terkait dengan desain kalian

8. Tuliskan konsep Teknik dan teknologi yang digunakan

9. Lakukan uji coba dengan teman kelompok, kemudian hasilnya di presentasikan

10. Tuliskan Kesimpulan dan saran atau upaya lebih baik

\section{HASIL DAN PEMBAHASAN}

Mahasiswa membuat solusi dari permasalahan yang ditemukan dengan mendaur ulang botol plastik bekas menjadi gantungan kunci. Botol plastik adalah limbah padat yang susah terurai sebanyak 75\% (Putra \& Yuriandala, 2010). 

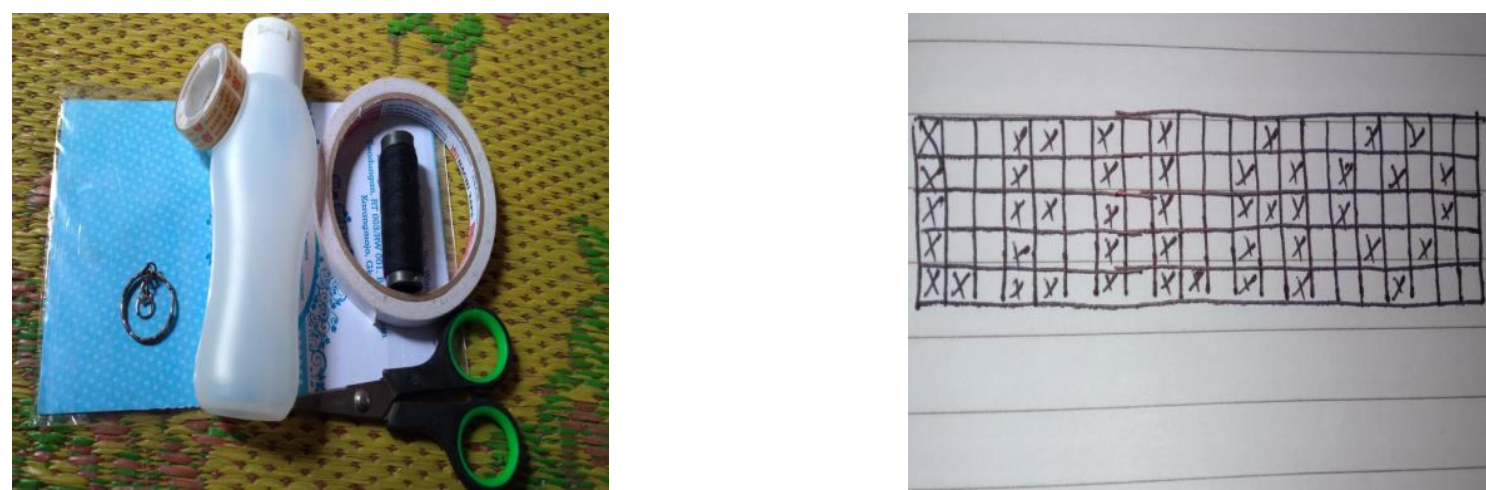

Gambar 1. Persiapan Pembuatan Gantungan Kunci

Proses perancangan dan pengerjaan proyek mahasiswa. Mahasiswa dapat mengerjakan konsep dasar science dengan pengamatan lingkungan di sekitar, mahasiswa dapat belajar dengan lingkungan di sekitar, hal ini sejalan dengan penelitian (Hw, 2012) dan (Yustiana et al., 2018) yang mengungkapkan beberapa alasan dalam penggunaan lingkungan di sekitar sekolah sebagai bahan, konteks dan sumber belajar yaitu: lingkungan dapat memperkaya bahan dan kegiatan belajar; penggunaan lingkungan memungkinkan terjadinya proses belajar yang memberikan pengalaman langsung sehingga membuat pembelajaran lebih bermakna dan fungsional; interaksi yang intensif dengan alam sekitar lebih cenderung menyiapkan perasaan dekat dan positif bagi peserta didik terhadap fenomena alam; memberikan tantangan untuk berpikir kritis dan memecahkan masalah, karena lingkungan menyediakan permasalahan yang ill-structured dan kompleks: mendukung perkembangan peserta didik pada bidang kognitif, emosional dan psikomotor. Pengembagan model pembelajaran berbasis lingkungan dan kearifan lokal sangat baik dikembangkan (Pratama, A T., 2020).

Penggunaan teknologi yang digunakan oleh mahasiswa yaitu mempresentasikan hasil kegiatan mereka dengan mengunggah di media sosial youtube (dapat dilihat pada gambar 2). Hal ini diyakini dapat menarik perhatian dan aktifitas mahasiswa. Menurut (Irwandani et al., 2019) dan (Cahyani et al., 2020) menyatakan bahwa media youtube sebagai alternatif digunakan dalam pembelajaran STEM. Link youtube dapat diakses pada https://youtu.be/d0aS_8cJFM8. 


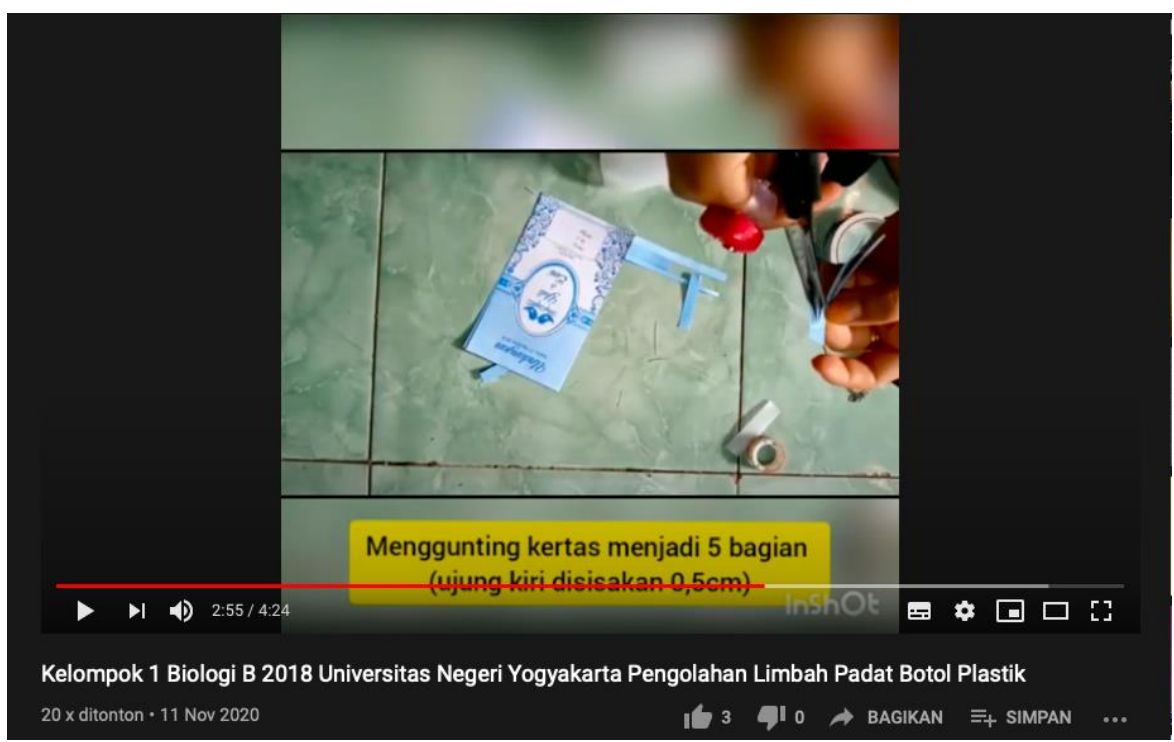

Gambar 2 Mengkumunikasikan Melalui Youtube

Konsep matematika yang digunakan oleh mahasiswa dalam pembelajaran STEM ini adalah bagaimana mahasiswa mengukur, mengobservasi dan membuat data botol plastik untuk dibuat menjadi gantungan kunci. (Hourigan \& Leavy, 2020) menyatakan bahwa pengumpulan data dan mempresentasikan data yang akan dibuat akan dapat mengambangkan stimulus siswa. Mahasiswa mendiskusikan tentang ukuran yang baik untuk pembuatan. Penyelidikan ini menyoroti bahwa matematika, dan khususnya statistik, dapat memimpin dalam kegiatan STEM terintegrasi, memberikan keterampilan dan praktik kritis yang diperlukan untuk memajukan penyelidikan, daripada hanya dilihat sebagai 'alat'(Smith et al., 2019) dan (Walker, 2017)
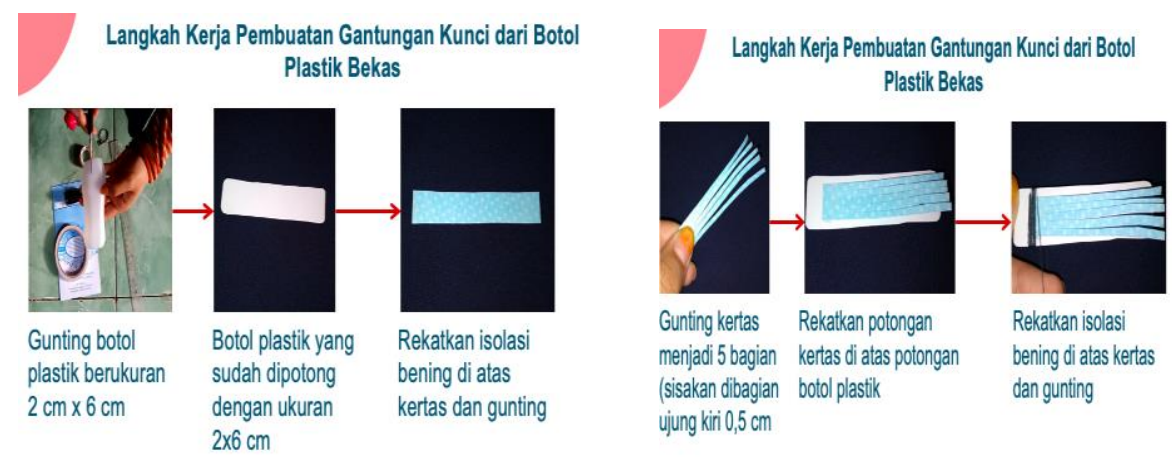

Gambar 3. Pengukuran untuk Pembuatan Gantungan Kunci 


\section{KESIMPULAN}

Mahasiswa dapat mengikuti pembelajaran berbasis proyek dengan STEM. Mahasiswa mengalami kesulitan dalam menganalisis kritis saran dan pembaikan produk.

\section{SARAN}

penelitian ini perlu dikembangkan pembelajaran STEM berbasis proyek yang dapat meningkatkan keterampilan kritis dan kreatif.

\section{DAFTAR PUSTAKA}

Cahyani, I., Sari, M., Tadris, J., Fakultas, K., Keguruan, I., \& Batusangkar, I. (2020). Pengembangan Vlog ( Video Blog ) Channel Youtube Berbasis STEM Pada Materi Laju Reaksi Kelas XI SMA / MA. Journal of Research and Education Chemistry (JREC), 2(2), 73-84. https://doi.org/10.25299/jrec.2020.vol2(2).5725

Fernandes, S., Mesquita, D., Flores, M. A., \& Lima, R. M. (2014). Engaging students in learning: Findings from a study of project-led education. European Journal of $\begin{array}{llr}\text { Engineering } \quad \text { Education, } & \text { 39(1), }\end{array}$ https://doi.org/10.1080/03043797.2013.833170

Hourigan, M., \& Leavy, A. M. (2020). Using integrated STEM as a stimulus to develop elementary students' statistical literacy. Teaching Statistics, 42(3), 77-86. https://doi.org/10.1111/test.12229

Hw, P. (2012). Biologi, Sains, Lingkungan dan Pembelajarannya dalam Upaya Peningkatan Kemampuan dan Karakter Siswa. Prosiding Seminar Biologi, 14-18. http://jurnal.fkip.uns.ac.id/index.php/prosbio/article/view/1011

Idin, S. (2011). An Overview of STEM Education and Industry 4 . 0. Research Highlights in STEM Education, 194-208.

Irwandani, I., Iqbal, M., \& Latifah, S. (2019). Pengembangan Video Blog (Vlog) Channel Youtube Dengan Pendekatan Stem Sebagai Media Alternatif Pembelajaran Daring. Inovasi Pembangunan: Jurnal Kelitbangan, 7(2), 135. https://doi.org/10.35450/jip.v7i2.140

Perignat, E., \& Katz-Buonincontro, J. (2019). STEAM in practice and research: An integrative literature review. Thinking Skills and Creativity, 31, 31-43. https://doi.org/10.1016/j.tsc.2018.10.002

Pratama, A T., et al. (2020). Analisis Kebutuhan Pengembangan Model. Jurnal Biolokus, $3(1), 1-18$.

Putra, H. P., \& Yuriandala, Y. (2010). Studi Pemanfaatan Sampah Plastik Menjadi Produk dan Jasa Kreatif. Jurnal Sains \&Teknologi Lingkungan, 2(1), 21-31. https://doi.org/10.20885/jstl.vol2.iss1.art3

Smith, C., Fitzallen, N., Watson, J., \& Wright, S. (2019). The Practice of Statistics for STEM: Primary Students and Pre-Service Primary Teachers Exploring Variation in 
Seed Dispersal. Teaching Science, 65(1), 38-47.

Stohlmann, M., Moore, T., \& Roehrig, G. (2012). Considerations for Teaching Integrated STEM Education. Journal of Pre-College Engineering Education Research, 2(1), 28-34. https://doi.org/10.5703/1288284314653

Walker, W. S. (2017). Integrated STEm or Integrated STEM? School Science and Mathematics, 117(6), 225-227. https://doi.org/10.1111/ssm.12234

Widayanti, Abdurrahman, A., \& Suyatna, A. (2019). Future Physics Learning Materials Based on STEM Education: Analysis of Teachers and Students Perceptions. Journal of Physics: Conference Series, 1155(1). https://doi.org/10.1088/17426596/1155/1/012021

Yustiana, I. A., Paidi, \& Mercuriani, I. S. (2018). Biology Factual Knowledge at Eleventh Grade of Senior High School Students in Pacitan based on Favorite Schools. Journal of Physics: Conference Series, 970(1). https://doi.org/10.1088/17426596/970/1/012029

Zubaidah, S. (2019). STEAM (Science, Technology, Engineering, Arts, and Mathematics): Pembelajaran untuk Memberdayakan Keterampilan Abad ke-21. Seminar Nasional Matematika Dan Sains, September, 1-18. 